\title{
DETENER LA PÉRDIDA DE BIODIVERSIDAD EN EUROPA (COUNTDOWN 2010): UNA CUESTIÓN PARA EL DEBATE DEL IV FORO DE BIODIVERSIDAD DE UICN-ESPAÑA
}

\section{Eduardo Galante Patiño}

Presidente del Comité español de UICN

galante@ua.es

\section{LA UICN, UNA FILOSOFÍA PARA CON- SERVAR DE LA NATURALEZA}

La Unión Mundial para la Naturaleza (UICN), fue fundada en el año 1948, y agrupa a Estados soberanos, agencias gubernamentales y una amplia gama de organizaciones no gubernamentales (grupos ecologistas, asociaciones naturalistas, sociedades científicas, etc.), constituyendo una alianza única de más de 900 organizaciones no gubernamentales (ONG's), gobiernos y cerca de 12.000 científicos y expertos de más de 138 países. La misión fundamental de la UICN se centra en ayudar a los pueblos de todo el Mundo a conservar la integridad y la diversidad de la naturaleza, buscando asegurar un uso equitativo de los recursos naturales.

A través de UICN son muchas las personas que han tomado conciencia del peligro que se cierne sobre la biodiversidad como consecuencia principalmente de las drásticas transformaciones de los ecosistemas, los profundos cambios de usos del suelo, la intensificación de los desarrollos urbanísticos y la creciente contaminación entre otras causas. El resultado de esta creciente actividad humana es una incesante pérdida de la diversidad biológica que arroja cifras escalofriantes y que evidencian que tenemos que hacer algo para frenar esta dramática desaparición de especies, siendo su resolución uno de los retos científicos más importantes del siglo XXI.

Es esta una empresa que tiene que integrar una visión multidisciplinar de conocimientos que gira indefectiblemente en torno a los seres vivos y a su historia pasada. La conservación no es únicamente un problema de conocer la presencia de los organismos vivos y sus funciones biológicas, es fundamentalmente un problema de compatibilizar desarrollo socioeconómico y cultural con la conservación de la biodiversidad, buscando la integración de conocimientos y distintas percepciones del problema a través del análisis efectuado por profesionales de diferentes campos del saber que sean capaces de abordar en conjunto el reto de la conservación de la naturaleza.

La conservación debe basarse en el sentido de la solidaridad y tener en cuenta que se necesita de la cooperación de todos. Los distintos países y admi- 
nistraciones tienen la obligación de plantear programas de inversión y contribuir con ayudas y disposiciones eficaces que permitan desarrollar actividades compatibles con la conservación de la biodiversidad, al tiempo que colmar las justas aspiraciones de desarrollo socioeconómico y cultural de los pueblos.

De acuerdo con esta filosofía que marca todas las actuaciones de los miembros de la UICN, el Comité Español celebra desde el año 2002, un Foro anual de Biodiversidad que desde su nacimiento ha constituido una plataforma de trabajo y encuentro para las organizaciones no gubernamentales, entidades científicas y administraciones. Estos foros son la expresión del Comité Español de la UICN de estar a la vanguardia de la discusión de los temas de conservación de la naturaleza, buscando el encuentro de los distintos sectores de la sociedad con el fin de analizar los problemas que afectan a la biodiversidad y proponer posibles soluciones para su conservación en el marco de programas dirigidos a lograr un mundo más justo y solidario.

Con el fin de dar cumplimiento a estos objetivos, se celebró en el Palacio de la Magdalena de Santander, entre los días 26 al 28 de mayo de 2005, el IV Foro de Biodiversidad de UICN (España) (Foto 1), cuya secretaría técnica y de organización ha estado a cargo de la Fundación Naturaleza y Hombre. Este Foro patrocinado por el gobierno de

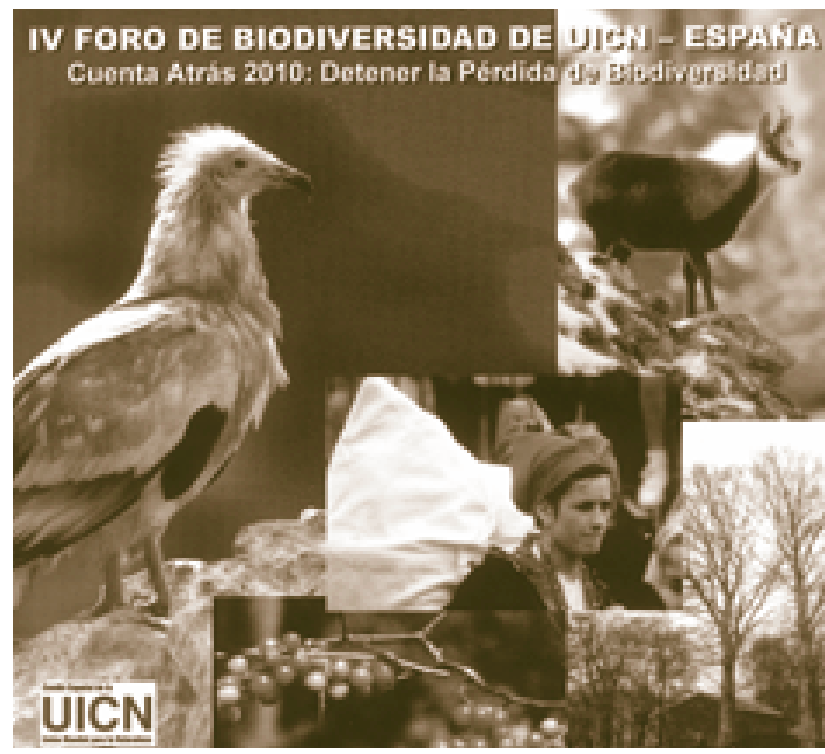

Foto 1
Cantabria y la Fundación Biodiversidad centró su tema de debate en la iniciativa europea de detener la pérdida de biodiversidad, lo que se conoce bajo el nombre de COUNTDOWN 2010. (Foto 2).

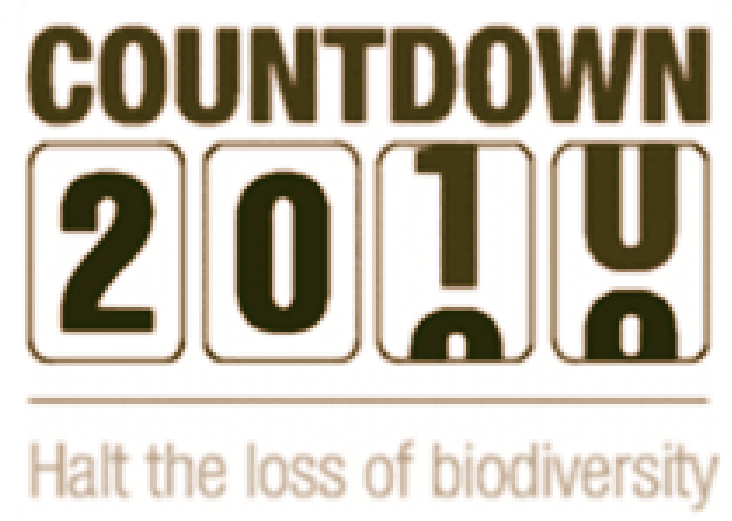

Foto 2

\section{LA INICIATIVA EUROPEA COUNTDOWN 2010}

Esta iniciativa surgió a nivel de la Unión Europea como un auténtico programa común que parte de la toma de conciencia de que el problema mundial de la pérdida de biodiversidad afecta también gravemente a Europa y repercute en sus ciudadanos. De este modo, bajo el paraguas de la Estrategia europea para el Desarrollo Sostenible y haciéndose eco de las múltiples acciones a nivel internacional sobre biodiversidad, cambio climático y desarrollo sostenible, etc., suscritos por sus países miembros, la Unión Europea adquirió el compromiso en la 5a Conferencia Europea de Medio Ambiente celebrada en el año 2003 en Kiev, de emprender acciones dirigidas a frenar la pérdida de su Diversidad Biológica con el horizonte final puesto en el año 2010.

Es una iniciativa que debiera constituir para los países miembros de la Unión Europea un auténtico programa de acción y compromiso, en el que España tiene obligatoriamente que jugar un papel importante, ya que posee el porcentaje más elevado de especies y endemismos de Europa. Nuestro país es uno de los principales componentes de la Europa 
Comunitaria que busca integrar políticas y aunar esfuerzos de sus ciudadanos buscando un futuro mejor para todos sus pueblos. Por otra parte España pertenece al Mediterráneo, auténtico crisol de culturas generado a lo largo de milenios, donde hemos ejercido de puente de unión entre una Europa que se ha desarrollado vertiginosamente y unos países del norte de África que se abren camino en un mundo cada vez más globalizado, en el que encontramos cada vez con mayor pujanza a las naciones de Iberoamérica con los que nos une lengua, cultura e historia y a los que nos debiera unir también una mayor y más eficiente cooperación.

En el marco de esta iniciativa europea de frenar la pérdida de biodiversidad, el estado español y las comunidades autónomas tienen la obligación de desarrollar normativas que pongan coto a la creciente y desmedida especulación de territorio y destrucción de la naturaleza en beneficio de tan sólo una parte de la sociedad (Foto 3); asociaciones ciudadanas y círculos científicos están obligados a contribuir a frenar la destrucción de biodiversidad que día a día se produce y los medios de comunicación debieran servir para concienciar a una sociedad que en ocasiones parece adormecida por no percibir la gravedad de la situación en que se encuentra el medio en el que vive. En definitiva todos somos responsables, si bien unos más que otros; cada uno

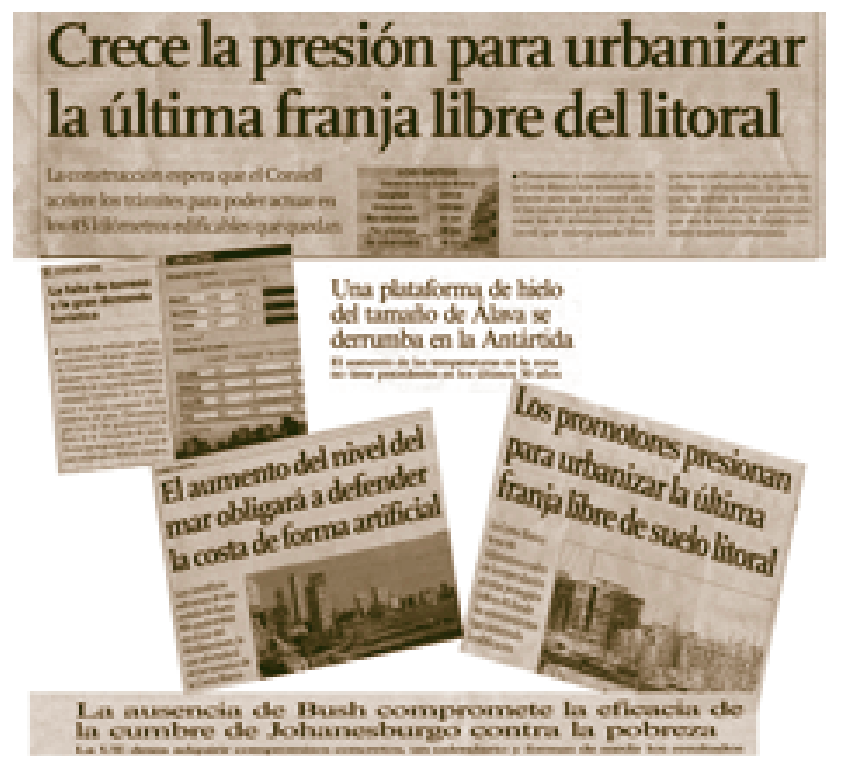

Foto 3: Actividad del hombre: una amenaza para la biodiversidad. de acuerdo con sus capacidades y responsabilidades en la toma de decisiones que la historia se encargará como siempre de juzgar.

\section{LAS LISTAS ROJAS COMO INSTRU= MENTO PARA CONOCER EL ESTADO DE LA BIODIVERSIDAD}

La UICN en Europa se encuentra implicada en el proceso de frenar la pérdida de biodiversidad jugando el papel que le corresponde como punto de encuentro de intereses, políticas y sectores sociales en ocasiones contrapuestos, pero buscando siempre el alcanzar acuerdos que permitan cumplir con el compromiso paneuropeo de frenar el proceso de pérdida de biodiversidad. Para cumplir este objetivo, tenemos que conocer el estado de nuestra diversidad biológica y uno de los instrumentos eficaces que tenemos son las Listas Rojas, una de las herramientas principales a las que se debe prestar toda la atención a través de la investigación y apoyo institucional, ya que son uno de los instrumentos mas importantes para lograr los objetivos de Countdown 2010. Por este motivo las Listas Rojas fueron objeto de debate prioritario en el marco del IV Foro de Biodiversidad, ya que desde la UICN entendemos que deben ser consideradas como un programa de constante recopilación de datos para poder proceder correctamente a la evaluación y diagnóstico periódico del estado de la biodiversi$\mathrm{dad}$, constituyendo excelentes indicadores del estado de conservación de los hábitat. Son por otra parte eficaces herramientas de protección del medio ya que proporcionan la información necesaria que puede ser utilizada en los programas de ordenación y protección del territorio.

\section{LA HUELLA ECOLÓGICA DE LA HUMA- NIDAD}

Si algo afecta gravemente a la conservación de la biodiversidad es la creciente apropiación energética de la que hace uso la especie humana, habiendo sido éste otro de los temas ampliamente debatidos en este IV Foro. La denominada Huella Ecológica, es un indicador del impacto que nuestras sociedades tienen sobre el medioambiente y que nos pone 
de manifiesto la relación existente entre el progreso del denominado estado del bienestar y la conservación de la biodiversidad. La huella ecológica mide la sostenibilidad ambiental y sopesa la demanda pasada y presente de la humanidad sobre los recursos naturales renovables de la tierra. Se define como el espacio necesario para generar los recursos que consumimos y asimilar los desechos que generamos. De este modo, la huella ecológica de un país es el área total que se requeriría para producir el alimento necesario para consumo de su población, cubrir la demanda de productos forestales, ocupación del territorio y consumo energético, unido todo ello al gasto derivado de absorber los desechos que resultan del consumo de energía y proporcionar espacio para infraestructuras.

El alto consumo energético es una de las principales causas de los elevados valores de nuestra huella ecológica. Con el objetivo de disminuir este índice se han desarrollado iniciativas que han sido difundidas por algunas Comunidades Autónomas españolas y que por su carácter práctico y didáctico, han despertado una gran interés en distintos sectores de la sociedad.

Este IV Foro de Biodiversidad celebrado en Cantabria a buen seguro ha de marcar un antes y un después en la conservación de la Biodiversidad en España, donde las competencias ambientales se diluyen y parcelan a través del estado de las autonomías, pero donde la unidad de acción debiera ser unánime y coordinada, ya que la Naturaleza no sabe de fronteras, de grupos o intereses partidistas. La Naturaleza nos está reclamando solidaridad, comprensión y colaboración de todos y este Foro ha querido contribuir a contrastar pareceres y obtener respuestas que nos ayuden a todos a encontrar el camino hacia COUNTDOWN 2010 . 